\title{
Erratum to: ESR1, FTO, and $U C P 2$ Genes Interact with Bariatric Surgery Affecting Weight Loss and Glycemic Control in Severely Obese Patients
}

\author{
Tsan-Hon Liou • Hsin-Hung Chen • Weu Wang • \\ Shu-Fen Wu • Yi-Chih Lee • Wei-Shiung Yang • \\ Wei-Jei Lee
}

Published online: 7 December 2011

(C) Springer Science + Business Media, LLC 2011

\section{Erratum to: OBES SURG}

DOI 10.1007/s11695-011-0457-3

In the original publication, the affiliation of author Hsin-Hung Chen was incomplete as worded. "Chang Jung University" should read as "Chang Jung Christian University."

The online version of the original article can be found at http://dx.doi. org/10.1007/s11695-011-0457-3.

T.-H. Liou

Department of Physical Medicine and Rehabilitation,

Shuang Ho Hospital, Taipei Medical University,

Taipei, Taiwan

T.-H. Liou

Graduate Institute of Injury Prevention,

Taipei Medical University,

Taipei, Taiwan

H.-H. Chen

Department of Medical Nutrition Therapies,

Pan-Chiao Cathay Hospital,

New Taipei City, Taiwan

W. Wang

Department of Surgery,

Taipei Medical University Hospital,

Taipei Medical University,

Taipei, Taiwan

S.-F. Wu

Department of Medical Administration,

Pan-Chiao Cathay Hospital,

New Taipei City, Taiwan
Y.-C. Lee

Department of International Business,

Ching Yun University,

Jhongli, Taiwan

\section{W.-S. Yang}

Graduate Institute of Clinical Medicine, College of Medicine, National Taiwan University,

Taipei, Taiwan

W.-J. Lee

Division of Surgery and Medical Therapy, Department of Surgery, Min-Sheng General Hospital,

Taoyuan, Taiwan

H.-H. Chen $(\square)$

Department of Nutrition and Health Sciences,

Chang Jung Christian University,

No. 396, Sec. 1, Changrong Rd., Gueiren Dist,

Tainan 71101, Taiwan

e-mail: d89623703@ntu.edu.tw 